University of Wollongong

Research Online

Faculty of Engineering and Information

Faculty of Engineering and Information

Sciences - Papers: Part A

Sciences

$1-1-2013$

\title{
Voltage unbalance emission assessment in interconnected power systems
}

Jayatunga Vitharanage Upuli Priyadarshani Jayatunga

University of Wollongong, jvupj453@uowmail.edu.au

Sarath Perera

University of Wollongong, sarath@uow.edu.au

Philip Ciufo

University of Wollongong, ciufo@uow.edu.au

Ashish Agalgaonkar

University of Wollongong, ashish@uow.edu.au

Follow this and additional works at: https://ro.uow.edu.au/eispapers

Part of the Engineering Commons, and the Science and Technology Studies Commons

Research Online is the open access institutional repository for the University of Wollongong. For further information contact the UOW Library: research-pubs@uow.edu.au 


\title{
Voltage unbalance emission assessment in interconnected power systems
}

\author{
Abstract \\ The International Electrotechnical Commission (IEC) Technical Report IEC/TR 61000-3-13:2008 considers \\ voltage unbalance (VU) emission assessment as a key aspect of the VU management of power systems. \\ Compliance assessment of unbalanced installations at the post connection stage is essential to ensure \\ that the limits set by the IEC VU emission allocation methodology in the pre-connection stage are met. \\ Although $\mathrm{VU}$ is known to be caused by load asymmetries and inherent network asymmetries, locating all \\ $\mathrm{VU}$ emission sources is not a straightforward process, especially in a network with interconnections. Such \\ assessment methodologies should ensure that the contributions from various sources of unbalance to \\ the total VU emission are determined using data which is not overly demanding. This paper presents \\ deterministic methodologies which can be used to assess constituent components of post-connection \\ VU level at the point of evaluation in an interconnected network utilising post connection voltage/current \\ measurements and known system parameters. The theoretical bases are developed to cover different \\ load types including induction motors. Emission assessment outcomes of different study systems \\ obtained by employing the proposed methodologies are verified using unbalanced load flow analysis. \\ Disciplines \\ Engineering I Science and Technology Studies \\ Publication Details \\ U. Jayatunga, S. Perera, P. Ciufo \& A. P. Agalgaonkar, "Voltage unbalance emission assessment in \\ interconnected power systems," IEEE Transactions on Power Delivery, vol. 28, (4) pp. 2383-2393, 2013.
}

This journal article is available at Research Online: https://ro.uow.edu.au/eispapers/2559 


\title{
Voltage Unbalance Emission Assessment in Radial Power Systems
}

\author{
U. Jayatunga, Student Member, IEEE, S. Perera, Member, IEEE, and P. Ciufo, Senior Member, IEEE
}

\begin{abstract}
Voltage unbalance (VU) emission assessment is an integral part in the VU management process where loads are allocated a portion of the unbalance absorption capacity of the power system. The International Electrotechnical Commission Report IEC/TR 61000-3-13:2008 prescribes a VU emission allocation methodology establishing the fact that the $\mathrm{VU}$ can arise at the point of common connection (PCC) due to both upstream network unbalance and load unbalance. Although this is the case for emission allocation, approaches for post connection emission assessment do not exist except for cases where the load is the only contributor to the VU at the PCC. Such assessment methods require separation of the post connection $\mathrm{VU}$ emission level into its constituent parts. In developing suitable methodologies for this purpose, the pre- and post-connection data requirements need to be given due consideration to ensure that such data can be easily established. This paper presents systematic, theoretical bases which can be used to assess the individual VU emission contributions made by the upstream source, asymmetrical line and the load for a radial power system. The methodology covers different load configurations including induction motors. Assessments obtained employing the theoretical bases on the study system were verified by using unbalanced load flow analysis in MATLAB and using DIgSILENT PowerFactory software.
\end{abstract}

Index Terms-power quality, voltage unbalance, current unbalance, voltage unbalance emission allocation, voltage unbalance emission assessment, system inherent asymmetry, load asymmetry

\section{INTRODUCTION}

$\mathbf{V}$ OLTAGE unbalance management in power systems requires approaches to allocate and assess VU emission levels in a systematic manner. In this regard, the IEC Technical report IEC/TR 61000-3-13:2008 [1] provides guiding principles to system operators and owners to determine the connection requirements of unbalanced installations to medium voltage (MV), high voltage (HV) and extra high voltage (EHV) public power systems. The philosophy of this report is similar to those of the counterpart IEC recommendations for harmonics (IEC 61000-3-6) [2] and flicker (IEC 610003-7) [3] allocation. Co-ordination of VU emission levels between different voltage levels of the power system are prescribed based on planning limits as reference values. The

U. Jayatunga, S. Perera and P. Ciufo are with the School of Electrical, Computer and Telecommunications Engineering, University of Wollongong, and are members of the Endeavour Energy Power Quality and Reliability Centre, NSW 2522, Australia (email: ppc@uow.edu.au).

NOTICE: this is the authors' version of a work that was accepted for publication. Changes resulting from the publishing process, such as peer review, editing, corrections, structural formatting, and other quality control mechanisms may not be reflected in this document. Changes may have been made to this work since it was submitted for publication. A definitive version was subsequently published in the IEEE Transactions on Power Delivery, vol 27, no. 3, Jul. 2012, DOI:10.1109/TPWRD.2012.2196294. global emission allowance is then derived through a general summation law considering upstream emission contribution through transfer coefficients. The ' $k_{u E}$ factor' approach is used to account for the unbalance that arises at the PCC caused by upstream supply system asymmetry, when apportioning the global emission allowance to unbalanced installations. A range of values for ' $k_{u E}$ factor' is given in [1] from which a suitable value can be selected for a system with some qualitatively characteristics.

Most of the available literature on voltage unbalance [4], [5] discuss its causes and effects and present related standards, definitions and mitigation techniques. Assessment of VU emission at the PCC with the help of the sequence energies is discussed in [6] and prediction of VU emission given by loads through unbalanced fundamental power is presented in [7]. None of the above work discuss or give methodologies that can be used to separate the individual emission contributions made by different sources of unbalance.

The work presented in [8] provides insights in relation to the approaches and concepts given in [1], including new methodologies to evaluate global VU emission due to load and line asymmetries. Although the unbalance arises due to unbalanced installations and inherent system asymmetries, determination of the level of contributions to the total VU emission at the point of evaluation (POE) is not a straightforward procedure due to the complex interactions that can take place between numerous sources, particularly in an interconnected network environment [9], [10]. The contribution of individual emission levels to the overall VU measured at the POE is often required with only knowledge of the pre- and post-connection voltage and current measurements in combination with some relatively easy to establish parameters.

In this regard, some preliminary work exists on VU emission assessment in $\mathrm{C} 4.109$ report [11] produced by the CIGRE/CIRED joint working group on emission assessment techniques. The same work summarised in [12] presents the ' $k_{u E}$ factor' in a more generalized manner. However, this formulation does not consider the load type dependency or sensitivity of ' $k_{u E}$ factor' to other system conditions. Thus, the proposed study makes a sufficiently rigorous and comprehensive fresh approach for compliance assessment providing further improvements to IEC work on VU management.

This paper presents deterministic approaches for the evaluation of individual VU emission contributions made by different sources of unbalance at the POE for a radial power system. The theoretical basis is developed to quantify the individual contributions made by upstream source unbalance, load asymmetry and line asymmetry at the POE for different load 
configurations. The mathematical models are verified using a 3-phase unbalanced load flow programs.

The paper is organised as follows: the general concepts associated with VU emission are described in Section II. The proposed mathematical modelling for the separation of different VU emission contributors is presented in Section III. Verification of the proposed methodology together with test system specifications are included in Section IV. Conclusions are given in Section V.

\section{General CONCEPTS OF VU EMISSION [11]}

According to IEC/TR 61000-3-13:2008 [1], the unbalance emission caused by an installation is the magnitude of the VU factor $\left(V U F=\left|\frac{U_{2}}{U_{1}}\right|\right)$ which the installation under consideration gives rise to at the POE. In many practical situations, the zero sequence unbalance is generally ignored, considering its insignificance compared to negative sequence unbalance from an equipment impact perspective and/or because of three-wire situations.

The sequence voltages at the POE can be described as a function of the sequence currents drawn by the connected installation and the upstream network (e.g. transmission line) sequence impedance matrix $Z_{012, t}$. Thus, the negative sequence voltage at the $\operatorname{POE}\left(U_{2}\right)$ can be expressed as in (1)

$$
U_{2}=U_{2, o c}-\left(Z_{20, t} I_{0}+Z_{21, t} I_{1}+Z_{22, t} I_{2}\right)
$$

where $U_{2, o c}$ is the open circuit negative sequence voltage which can be obtained from pre-connection voltage measurement $\left(U_{2, \text { pre-connection }}\right)$ at the POE. $U_{2}$ can be obtained from the post-connection voltage $\left(U_{2, \text { post-connection }}\right)$ at the POE. The following comments are applicable to the three impedance voltage drop terms in (1):

- $Z_{20, t}$ is relatively small and $I_{0}=0$ in many situations and hence $Z_{20, t} I_{0}$ can be ignored.

- $Z_{21, t} I_{1}$ is the negative sequence voltage that arises as a result of the asymmetrical upstream network itself and can be defined as the system inherent unbalance $\left(U_{2, i \text { (line) })}\right)$. This term can be of significance since $I_{1}$ is usually large. $Z_{21, t}$ exists only if the upstream network is asymmetrical.

- $Z_{22, t} I_{2}$ can be of significance if there is an unbalance current due to load unbalance (assuming that there are no contributions to $I_{2}$ from upstream unbalance and asymmetrical upstream impedances). Therefore, this term is the negative sequence voltage which arise as a result of load unbalance and is defined as the load unbalance emission $\left(U_{2, i(\text { load })}\right)$.

Hence, ignoring the term $Z_{20, t} I_{0}, U_{2}$ can be re-expressed as shown in (2):

$$
U_{2}=U_{2, o c}-\left(Z_{21, t} I_{1}+Z_{22, t} I_{2}\right)=U_{2, o c}+U_{2, i}
$$

where $U_{2, i}$ is the VU emission resulted from the connection of installation which consists of asymmetrical load and line contributions.

The approach given in CIGRE/CIRED report on emission assessment techniques [11] is to evaluate unbalance emission levels based on pre-connection and post-connection measurements at the POE. Having suitable measurement results with phase angle information (pre- and post-connection), the total emission $U_{2, i}$ can naturally be established as given by (3).

$$
U_{2, i}=U_{2, \text { post-connection }}-U_{2, \text { pre-connection }}
$$

Accordingly, the emission level that arises as a result of a particular installation can lead to an increase or a decrease of the resultant unbalance level at the POE. At the postconnection of the installation, if the net unbalance level decreases, no emission assessment has to be carried out in relation to the particular installation. Conversely, if the net unbalance increases, the fraction of the emission level which the installation is responsible for $\left(U_{2, i(\mathrm{load})}\right)$ has to be evaluated.

So, challenge lies in the decomposition of $U_{2}$ to determine the individual contributions made by different sources of unbalance in the network (i.e., background unbalance voltage, asymmetrical supply network impedances, and the installation in question) for which a comprehensive methodology or methodologies do not exist.

In the straightforward case where the VU at the POE arises only as a result of installation asymmetry, $U_{2, i(\text { load }) \text {, can }}$ be established using the well known result employing the quantities of current unbalance factor $(C U F$ - i.e., the ratio of negative sequence to positive sequence current), load VA loading level $\left(S_{i}\right)$ and the short circuit capacity $\left(S_{s c}\right)$ as given by (4);

$$
\left|\frac{U_{2, i(\text { load })}}{U_{1}}\right|=\frac{S_{i}}{S_{s c}}|C U F|
$$

Further to (4), the VU emission that arises at the POE due to an asymmetrical upstream network (or line) asymmetry $\left(U_{2, i(\text { line })}\right)$ can be estimated using:

$$
\frac{U_{2, i(\text { line })}}{U_{1}}=\frac{S_{i}}{S_{s c}}\left|\frac{Z_{12}}{Z_{1}}\right|
$$

where, $Z_{12}$ is the positive-sequence negative-sequence coupling impedance of the upstream network, and $Z_{1}$ is the positive-sequence impedance of the upstream network.

The specific results given by (4) and (5) can be used individually to determine the contributions to the $\mathrm{VU}$ at the POE made by an installation or the network. However, they are not sufficiently comprehensive to be used with preand post-connection measurements to separate the VU at the POE into constituent components. Further, the impact of the upstream source unbalance ${ }^{1}$ on the POE is not accounted for by these results. Hence, it can be noted that a holistic approach and fresh formulations are required to separate the VU measurements at the POE into its constituent components, which forms the thrust of this paper. The specific results given by (4) and (5) can be shown to be intrinsically built into the mathematical formulations that will be presented in this paper.

${ }^{1}$ Can be considered as a Thévenin equivalent unbalance voltage. 


\section{EVALUATION OF INDIVIDUAL UNBALANCE EMISSION CONTRIBUTIONS AT THE POE: THEORETICAL BASES}

A deterministic approach is proposed which forms the bases for evaluation of the individual contributions made by the installation asymmetry, upstream network asymmetry and the upstream source unbalance on the total VU emission at the POE. Different load types are considered in developing this unbalance emission evaluation procedure and the corresponding results are verified by employing a 3-phase unbalanced load flow analysis and through other simulations.

The linearity property of negative sequence variables [1], [8] is employed in establishing the new methodology for the separation of different VU contributors. That is, the resultant negative sequence voltage at the POE which arises as a result of the interaction of various sources of unbalance, is equal to the phasor summation of the negative sequence voltage components caused by individual sources of unbalance at the POE.

The theoretical bases of the VU separation methodology is developed considering the radial power system as shown in Fig. 1, in reference to which the following points are to be noted:

- The power system is assumed to operate under sinusoidal steady state conditions.

- The POE is considered to be dedicated only to the unbalanced installation under consideration.

- Presence of unbalance at the POE is caused by load asymmetry, network asymmetry and unbalance in the source (background unbalance). Therefore all power system elements (source, load and network) are analysed in a generalised manner noting that all of these components can contribute to the total unbalance emission at the POE.

- Zero sequence behaviour is ignored assuming three wire systems ${ }^{2}$.

- Theoretical bases are developed in terms of complex voltage/current unbalance factors at the POE. Thus, it is assumed that all voltage/current measurements in either pre- or post-connection stages at the POE are obtained as synchronised phasor quantities.

- Installation (load) is represented as a coupled impedance matrix in the case of passive loads (coupling impedances are present when converting unequal decoupled phase impedances into sequence domain) and as a decoupled impedance matrix in the case of induction motors in the sequence domain.

\section{A. Separation of VU emission contributors: passive loads}

1) Constant Impedance Loads: Referring to the radial power system shown in Fig. 1, positive and negative sequence voltages at the sending end (i.e., the source end) ( $U_{1 \text {,send }}$ and $U_{2 \text {,send }}$ ) can be written as given below:

$$
\begin{aligned}
& U_{1, \text { send }}=U_{1, \text { rec }}+\left(Z_{11, t} I_{1}+Z_{12, t} I_{2}\right) \\
& U_{2, \text { send }}=U_{2, \text { rec }}+\left(Z_{21, t} I_{1}+Z_{22, t} I_{2}\right)
\end{aligned}
$$

\footnotetext{
${ }^{2}$ As stated in Section II, IEC/TR 61000-3-13 considers that zero sequence behaviour can be controlled through system design and maintenance.
}

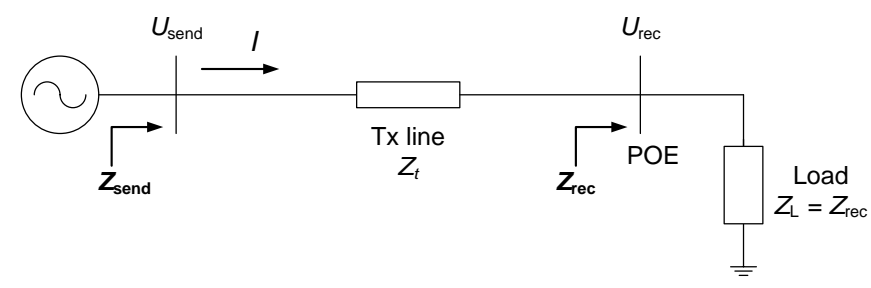

Fig. 1. Radial power system

where $U_{1 \text {,rec }}$ and $U_{2 \text {,rec }}$ are positive and negative sequence voltages at the POE respectively. $I_{1}$ and $I_{2}$ are positive and negative sequence currents flowing in the system respectively. $Z_{x y, t}$ is sequence impedance of the transmission line ${ }^{3}$.

$I_{1}$ and $I_{2}$ can be found in terms of load parameters as given in (8) and (9). Detailed derivations of $I_{1}$ and $I_{2}$ are given in Appendix A.

$$
\begin{gathered}
I_{1}=\frac{U_{1, \mathrm{rec}}}{Z_{11, \mathrm{rec}}} \\
I_{2}=-\frac{Z_{21, \mathrm{rec}} U_{1, \mathrm{rec}}}{Z_{11, \mathrm{rec}} Z_{22, \mathrm{rec}}}+\frac{U_{2, \mathrm{rec}}}{Z_{22, \mathrm{rec}}}
\end{gathered}
$$

where, $Z_{x y \text {,rec }}$ is the sequence impedance seen at the POE (equal to load impedance).

Case I: The upstream source is balanced. In this case, as $U_{2 \text {,send }}=0$ in (7), the unbalance at the POE arises as a result of load asymmetry and line asymmetry only. Substitution of $I_{1}$ and $I_{2}$ from (8) and (9) into (7) results in the VU factor at the POE $\left(V U F_{P O E}\right)$ as follows.

$$
V U F_{P O E}=\frac{U_{2, \mathrm{rec}}}{U_{1, \mathrm{rec}}}=\frac{Z_{22, t} Z_{21, \mathrm{rec}}-Z_{21, t} Z_{22, \mathrm{rec}}}{\left(Z_{22, \mathrm{rec}}+Z_{22, t}\right) Z_{11, \mathrm{rec}}}
$$

Employing the fact that the negative sequence impedance of the network $\left(Z_{22}\right)$ is equal to its positive sequence impedance $\left(Z_{11}\right), V U F_{P O E}$ can be rewritten as shown by (11).

$$
V U F_{P O E}=\frac{Z_{22, t} Z_{21, \mathrm{rec}}}{\left(Z_{11, \mathrm{send}} Z_{11, \mathrm{rec}}\right)}-\frac{Z_{21, t}}{Z_{11, \mathrm{send}}}
$$

where $Z_{11, \text { send }}=Z_{11, \text { rec }}+Z_{11, t}$. By defining voltage regulation

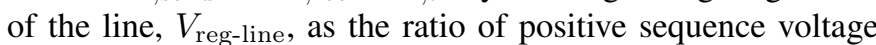
drop in the network (line) to positive sequence voltage at the receiving end as given by (12), the expression for $V U F_{P O E}$ can be further modified as shown in (13).

$$
\begin{gathered}
V_{\text {reg-line }}=\frac{U_{1, t}}{U_{1, \text { rec }}}=\frac{Z_{11, t}}{Z_{11, \text { rec }}}=\frac{Z_{22, t}}{Z_{11, \text { rec }}} \\
V U F_{P O E}=\frac{Z_{21, \text { rec }}}{Z_{11, \text { rec }}} \frac{V_{\text {reg-line }}}{\left(1+V_{\text {reg-line }}\right)} \\
-\frac{Z_{21, t}}{Z_{11, t}} \frac{V_{\text {reg-line }}}{\left(1+V_{\text {reg-line }}\right)}
\end{gathered}
$$

Referring to Eqn. (13), if the load is symmetrical (i.e., the coupling impedance $\left(Z_{21 \text {,rec }}=0\right)$, the unbalance at the POE arises as a result of the network (line) only which can be assessed using the factor $\frac{Z_{21, t}}{Z_{11 t}} \frac{V_{\text {reg-line }}}{\left(1+V_{\text {reg-line }}\right)}$. Conversely, for a symmetrical network, the positive-sequence negative-sequence

\footnotetext{
${ }^{3} x$ and $y$ are replaced by 1 and 2 which stand for positive sequence and negative sequence respectively.
} 
coupling impedance $Z_{21, t}=0$ and the VU that arises at the POE due to load asymmetry can be established using the factor $\frac{Z_{21, \text { rec }}}{Z_{11 \text {,rec }}} \frac{V_{\text {reg-line }}}{\left(1+V_{\text {reg-line }}\right)}$.

For the case where the installation is symmetrical but the supply network is asymmetrical (i.e., $\left(Z_{21 \text {,rec }}=0, Z_{21, t} \neq 0\right)$, it may be demonstrated that the VU at the POE given by the rigorous outcome of (13) is similar to the result given by (5).

Case II: The upstream source is unbalanced $\left(U_{2 \text {,send }} \neq 0\right)$. In this case, the source, installation and the network (line) can together make contributions to the total VU emission at the POE. So, When $U_{2, \text { send }} \neq 0$ in (7) the $V U F_{P O E}$ can be found following the same steps as described in Case I and shown to be depicted by three components as represented by (14):

$$
\begin{aligned}
V U F_{P O E}=V U F_{\text {source }}+ & \frac{Z_{21, \text { rec }}}{Z_{11, \text { rec }}} \frac{V_{\text {reg-line }}}{\left(1+V_{\text {reg-line }}\right)} \\
& -\frac{Z_{21, t}}{Z_{11, t}} \frac{V_{\text {reg-line }}}{\left(1+V_{\text {reg-line }}\right)}
\end{aligned}
$$

Eqn. (14) shows that the source unbalance transfers to the POE with no attenuation, whereas the network (line) and installation contributions to the POE are similar to those in Case I.

$$
\begin{gathered}
U_{2, \text { source }}=V U F_{\text {source }} \\
U_{2, i(\text { load })}=V U F_{P O E \text {-load }}=\frac{Z_{21, \text { rec }}}{Z_{11, \text { rec }}} \frac{V_{\text {reg-line }}}{\left(1+V_{\text {reg-line }}\right)} \\
U_{2, i(\text { line })}=V U F_{P O E \text {-line }}=-\frac{Z_{21, t}}{Z_{11, t}} \frac{V_{\text {reg-line }}}{\left(1+V_{\text {reg-line }}\right)}
\end{gathered}
$$

2) Constant Power Loads: Eqn. (14) can be further modified, in terms of voltage and current unbalance factors, by eliminating impedance terms associated with the installation (i.e., $Z_{21 \text {,rec }}$ and $Z_{11 \text {,rec }}$ ) to the form given in (15) (see Appendix B for the proof). This process will facilitate the evaluation of VU emission related to loads of which impedance details are not available.

The VU emission that arises at the POE as a result of load asymmetry only is:

$$
V U F_{\text {load }}=\left(V U F_{P O E}-C U F\right) \frac{V_{\text {reg-line }}}{\left(1+V_{\text {reg-line }}\right)}
$$

Eqn. (15) can be shown to be a rigorous and a general form of the result given by (4). Incorporating (15), the VU at the POE for constant power loads can be re-expressed as shown in (16):

$$
\begin{aligned}
V U F_{P O E}=V U F_{\text {source }} & \\
& +\left(V U F_{P O E}-C U F\right) \frac{V_{\text {reg-line }}}{\left(1+V_{\text {reg-line }}\right)} \\
& -\frac{Z_{21, t}}{Z_{11, t}} \frac{V_{\text {reg-line }}}{\left(1+V_{\text {reg-line }}\right)}
\end{aligned}
$$

3) Constant Current Loads: Although constant current loads draw currents of equal magnitude in the three supply phases regardless of the prevailing voltage balance/unbalance conditions, negative sequence current associated with load current can be significant as a result of unequal phase angle displacements of line current. This means, asymmetrical constant current load behaviour can be considered to the similar manner how the constant power load was previously examined for VU emission assessment.

\section{B. Separation of $V U$ emission contributors: induction motors} (IM)

Naturally, three phase induction motors do not possess any inherent unbalance other than the fact that their operation is affected by the supply source unbalance. Further three phase induction motors are known to improve (reduce or compensate) pre-existing VU level at a PCC. Therefore, this specific case is aimed at quantifying the $\mathrm{VU}$ emission compensation provided at the POE by three phase induction motors.

The passive load in Fig. 1 is replaced with a 3-phase induction motor which can be represented by three decoupled impedances in the sequence domain. Therefore, expressions for positive and negative sequence motor currents $\left(I_{1, m}\right.$ and $I_{2, m}$ respectively) can be established by:

$$
\begin{aligned}
& I_{1, m}=\frac{U_{1, \mathrm{rec}}}{Z_{1, m}} \\
& I_{2, m}=\frac{U_{2, \mathrm{rec}}}{Z_{2, m}}
\end{aligned}
$$

where $Z_{1, m}$ and $Z_{2, m}$ are the positive and negative sequence impedances, respectively, of the motor which can be established from the motor equivalent circuit.

Substitution of the sequence currents given by (17) and (18) in (6) and (7) gives the total VU at the POE as given by (19):

$$
\begin{aligned}
V U F_{P O E}=\left(\frac{Z_{2, m}}{Z_{1, m}}\right) & \left(\frac{Z_{1, m}+Z_{11, t}}{Z_{2, m}+Z_{22, t}}\right) V U F_{\text {source }} \\
& -\left(\frac{Z_{2, m}}{Z_{1, m}}\right)\left(\frac{Z_{21, t}}{Z_{22, t}+Z_{2, m}}\right)
\end{aligned}
$$

Using (19), the improvement made by the connection of three phase induction motor on an already unbalanced supply system can be noted by considering the special case where the transmission line is symmetrical (i.e., $Z_{21, t}=0$ ). For this case, the VU emission at the POE is the source VU level $\left(V U F_{\text {source }}\right)$, scaled by a factor $\left(\frac{Z_{2, m}}{Z_{1, m}}\right)\left(\frac{Z_{1, m}+Z_{11, t}}{Z_{2, m}+Z_{22, t}}\right)$, having a magnitude less than unity, which incorporates positive and negative sequence impedances of the line and the motor.

From (19) the influence made by the asymmetrical supply network (line) on the total unbalance is given by the factor $\left(\frac{Z_{2, m}}{Z_{1, m}}\right)\left(\frac{Z_{21, t}}{Z_{22, t}+Z_{2, m}}\right)$.

\section{Separation of $V U$ emission contributors: mix of passive and induction motor loads}

When the radial system supplies a mix load, the total line current can be found as the summation of the individual positive $\left(I_{1, P L}\right.$ and $\left.I_{1, m}\right)$ and negative sequence $\left(I_{2, P L}\right.$ and $I_{2, m}$ ) currents drawn by the passive and induction motor loads. Accordingly, the negative sequence voltage at the POE given in (7) can be modified and the VUF at the POE that arises as a result of the mixed load can be shown with appropriate substitutions to take the form of (20):

$$
V U F_{P O E}=A\left(V U F_{\text {source }}\right)+B+C
$$


where the factors $\mathrm{A}, \mathrm{B}$ and $\mathrm{C}$ are given by the following expressions:

$$
\begin{gathered}
A=\frac{1+\frac{Z_{11, t}}{Z_{11, \mathrm{rec}}}}{1+\frac{Z_{22, t}}{Z_{2, m}}+\frac{Z_{22, t}}{Z_{22, P L}}} \\
B=\frac{\frac{Z_{21, P L}}{Z_{22, P L}} \frac{Z_{22, t}}{Z_{11, P L}}}{1+\frac{Z_{22, t}}{Z_{22, m}}+\frac{Z_{22, t}}{Z_{22, P L}}} \\
C=-\frac{\frac{Z_{21, t}}{Z_{11, \mathrm{rec}}}}{1+\frac{Z_{22, t}}{Z_{2, m}}+\frac{Z_{22, t}}{Z_{22, P L}}}
\end{gathered}
$$

Referring to (22), if the passive load is symmetrical, the positive sequence negative sequence coupling impedance, $Z_{21, P L}$ is zero and hence $B=0$. This means, the factor $B$ can be considered as the VU emission contribution made by the load asymmetry.

Referring to (23), if the transmission line is transposed, the positive sequence negative sequence coupling impedance of the line, $Z_{21, t}$ is zero. Accordingly, $C=0$ and hence the factor $C$ can be considered as the VU emission contribution that arises as a result of the line asymmetry.

If both the passive load and the transmission line are symmetrical (i.e., $B=C=0$ ), then the VUF at the POE is given by $A$ ( $\left.V U F_{\text {source }}\right)$. Thus, the factor $A$ given by (21) (of which the magnitude is less than unity) can be interpreted as the upstream or source VU modification factor that needs to be considered in the presence of an induction motor load.

These three factors, $A, B$ and $C$, can be re-expressed in terms of known system parameters by introducing the voltage regulation of the line ( $\left.V_{\text {reg-line }}\right)$ and the current unbalance factor of the passive load $\left(C U F_{P L}\right)$.

Therefore, the individual VU emission contributions made by the induction motor, $U_{2, i(\mathrm{IM})}$, the passive load $U_{2, i(\mathrm{PL})}$, and the upstream network $U_{2, i \text { (line) }}$, at the POE can be summarised as shown in (24), (25) and (26).

\section{VERIFICATION OF THE METHODOLOGY}

\section{A. Test network and the loads}

A radial network based on a $12.47 \mathrm{kV}$ test system given in [8] was used to determine $\mathrm{VU}$ emission contributions made by the different sources. This system consists of the upstream source, untransposed network (line), and the load including passive load types (constant impedance, constant current or constant power loads), three-phase induction motor loads and a mix of these load types. The passive load types were modelled employing the exponential load models [13] as given by (27):

$$
P=P_{0}\left(\frac{V}{V_{0}}\right)^{\alpha} \text { and } Q=Q_{0}\left(\frac{V}{V_{0}}\right)^{\beta}
$$

where $P, Q$ are the active and reactive power consumed by the load at voltage $V$. The terms $P_{0}, Q_{0}$ represent the rated active and reactive powers, respectively, at the nominal voltage $V_{0}$. The exponents $\alpha$ and $\beta$ are the voltage coefficients of the active and reactive powers, respectively. For constant power loads, $\alpha, \beta=0$, for constant current loads, $\alpha, \beta=1$ and for constant impedance loads, $\alpha, \beta=2$.

The details of the test system are as follows.
- System details: $12.47 \mathrm{kV}, 60 \mathrm{~Hz}$, three wire

- $12.47 \mathrm{kV}$ untransposed line:

- Tower construction details: $1.143 \mathrm{~m}$ flat and horizontal

- Conductor data:

$*$ Geometric mean radius $=7.7724 \mathrm{~mm}$

$*$ AC resistance $=0.19014 \Omega / \mathrm{km}$

$*$ Earth resistivity $=100 \Omega . \mathrm{m}$

- Calculated line impedance matrix $\left(\left[Z_{a b c}\right] / \mathrm{km}\right)$

$$
\begin{array}{lll}
0.2494+j 0.8748 & 0.0592+j 0.4985 & 0.0592+j 0.4462 \\
0.0592+j 0.4985 & 0.2494+j 0.8748 & 0.0592+j 0.4985 \\
0.0592+j 0.4462 & 0.0592+j 0.4985 & 0.2494+j 0.8748
\end{array}
$$

- Load:

- Passive load : A 10 MVA/1 MVA three phase load with lagging power factors of $0.85,0.90$ and 0.50 in phases $\mathrm{a}, \mathrm{b}$ and $\mathrm{c}$ respectively.

- Induction motor load : A $2250 \mathrm{hp}, 2.3 \mathrm{kV}, 3$ phase induction motor of which the equivalent circuit parameters are given in [14].

An unbalanced load flow program written in MATLAB in conjunction with unbalanced load flow analysis using DIgSILENT were used to verify the outcomes of the mathematical formulations. For brevity, the VU separation outcomes presented in the following subsections cover only a limited number of cases addressed by the formulations:

- passive load - constant power type,

- induction motor load, and

- mix of passive and induction motor load.

\section{B. Passive loads : Constant Power loads}

The radial power system with a $3.2187 \mathrm{~km}$ line (voltage regulation of the line $\left.\left(\left|V_{\text {reg-line }}\right|\right)-9.6 \%\right)$ supplying 10 MVA single phase constant power type load set was simulated with the unbalanced load flow program in MATLAB. The VU emission separation outcomes (the general application of Eqn (16)) is illustrated in Fig. 2 using phasor diagrams for four different upstream source unbalance levels. The data (generated from unbalanced load flow program) which is used to produce phasor diagrams is given in Appendix C.

The phasor diagrams of Fig. 2 show VU emission in terms of individual VU factors (indicated as a percentage alongside the individual phasors) that arise at the POE as a result of the different sources of unbalance. In these diagrams:

- $V U F_{\text {source }}$ represents the VU emission at the upstream or source (i.e., pre-connection VU emission at the POE) which is zero for case (a) but finite for cases (b)-(d)

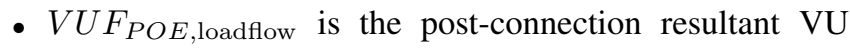
emission at the POE obtained using unbalanced load flow studies

- $V U F_{P O E, \text { cal }}$ is the post-connection resultant VU emission at the POE evaluated using the formulation

- phasor $V U F_{P O E \text {,load }}$ represents the VU emission at the POE caused by the load asymmetry evaluated using the formulation

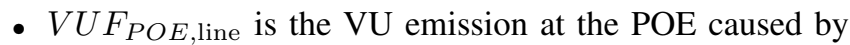
the line asymmetry evaluated using the formulation 
The upstream source voltage unbalance modified by the induction motor $(A)$

$$
U_{2, i(I M)}=\left(\frac{Z_{1, m} Z_{2, m}\left(1+V_{\text {reg-line }}\right)}{Z_{1, m} Z_{2, m}\left(1+V_{\text {reg-line }}\right)+Z_{22, t}\left(Z_{1, m}-Z_{2, m}\right)}\right) V U F_{\text {source }}
$$

Asymmetrical passive load contribution $(B)$

$$
U_{2, i(\mathrm{PL})}=\left(V U F_{P O E}-C U F_{P L}\right)\left(\frac{Z_{1, m} Z_{2, m}\left(V_{\text {reg-line }}-\frac{Z_{22, t}}{Z_{1, m}}\right)}{Z_{1, m} Z_{2, m}\left(1+V_{\text {reg-line }}\right)+Z_{22, t}\left(Z_{1, m}-Z_{2, m}\right)}\right)
$$

Asymmetrical line contribution $(C)$

$$
U_{2, i \text { (line) }}=-\frac{Z_{21, t}}{Z_{11, t}}\left(\frac{Z_{1, m} Z_{2, m} V_{\text {reg-line }}}{Z_{1, m} Z_{2, m}\left(1+V_{\text {reg-line }}\right)+Z_{22, t}\left(Z_{1, m}-Z_{2, m}\right)}\right)
$$

The reader should note that the $V U F_{P O E \text {,cal }}$ is represented as the reference phasor with a phase angle of zero degrees although this angle may take on any value. Accordingly, all other vectors are represented with respect to the above reference phasor.

The nearly coincident resultant VU emission vectors with nearly similar magnitudes representing the VU at the POE established using the formulation and through load flow analysis, demonstrate that the mathematical formulation is sufficiently accurate. In addition, the following further conclusions can be drawn:

- For case (a), the cancellation of VU emissions made by load $(1.15 \%)$ and line $(0.78 \%)$ are seen to help lower the VU emission at the POE to $(0.68 \%)$.

- The magnitudes of VU contributions made by the network are seen to be similar $(0.78 \%, 0.78 \%, 0.76 \%$, $0.77 \%$ ) in all four cases although they exhibit different phase shifts with respect to the reference phasor. The similarity in magnitude can be attributed to the fact that the passive load VA is nearly the same for all cases.

- The upstream source unbalance is seen to have some degree of influence on the VU emission by the load (compare $1.15 \%$ with $1.17 \%, 1.06 \%$ and $1.4 \%$ ).

The resultant VU emission at the POE is seen to be significantly influenced not only by the magnitudes of the individual contributions but also by their phasor orientations. In other words, significant cancellations or strengthening (amplifications) may be observed between load pre-connection and load post-connection stages.

\section{Induction motor load}

The $12.47 \mathrm{kV}$ radial power system with a $5 \mathrm{~km}$ line $\left(\left|V_{\text {reg-line }}\right|-5.5 \%\right)$ supplying a 3-phase induction motor load (see Section IV-A) was modelled using DIgSILENT to validate the proposed VU emission separation methodology. A threephase two-winding $\mathrm{Yg}$-Yg connected transformer model was used as the motor service transformer with a voltage ratio: $12.47 / 2.3 \mathrm{kV}$ and a leakage reactance of $5 \% \mathrm{pu}$.

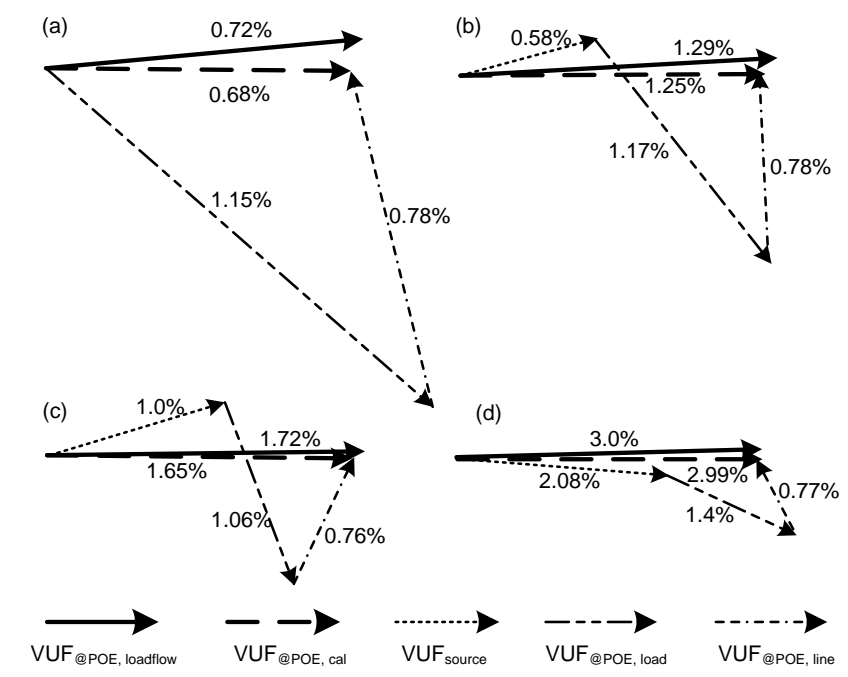

Fig. 2. Separation of VU emission at POE with different source unbalance levels: unbalanced constant power load, untransposed line. (a). $V U F_{\text {source }}$ $=0 \% \quad$ (b). $. V U F_{\text {source }}=0.58 \%$ (c). $V U F_{\text {source }}=1.0 \%$ (d). $V U F_{\text {source }}=$ $2.08 \%$

The separation of the VU emission (the application of (19)) at the POE is shown in Fig. 3 using phasor diagrams for four different upstream VU levels. The general comments applicable for the phasor diagrams relevant to the case of passive loads is applicable here as well. Further, the resultant VU emission vectors representing the VU at the POE established using the formulation and through simulation are in close agreement thus proving the validity of the formulation.

Based on the phasor diagrams of Fig. 3, following further conclusions can be drawn:

- The improvement in the VU emission at the POE that usually takes place when 3-phase induction motors are connected is clearly evident which can be seen by examining the magnitudes of $V U F_{\text {source }}$ and $\left.V U F_{P O E, I M}\right)$ for cases (b)-(d) (compare $0.58 \%, 1.16 \%, 2.33 \%$ with 
$0.47 \%, 0.94 \%, 1.88 \%$ respectively).

- The scaling factor associated with this reduction (see (18)) is not seen to introduce a significant phase shift between the pre- and post-connected VU emission vectors $V U F_{\text {source }}$ and $V U F_{P O E, I M}$.

(a)

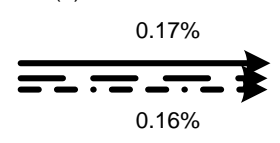

(c)

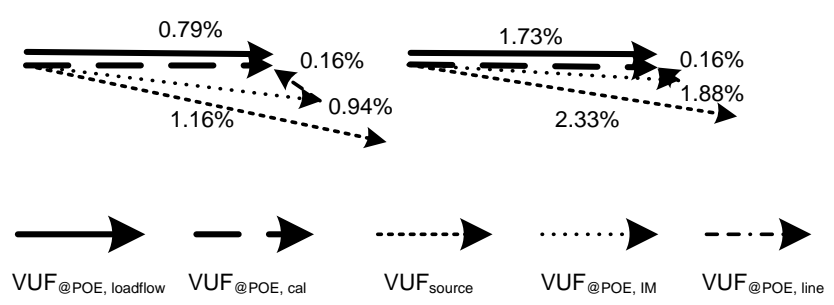

Fig. 3. Separation of VU emission at POE with different source unbalance levels: induction motor load, untransposed line. (a). $V U F_{\text {source }}=0 \%$ (b). $V U F_{\text {source }}=0.58 \%$ (c). $V U F_{\text {source }}=1.16 \%$ (d). $V U F_{\text {source }}=2.33 \%$

\section{Mix of passive load and induction motor load}

The $12.47 \mathrm{kV}$ radial power system consisting of $5 \mathrm{~km}$ untransposed line supplying a mixed load is considered here. $2.3 \mathrm{kV}, 2250 \mathrm{hp} \mathrm{3-phase} \mathrm{induction} \mathrm{motor} \mathrm{(connected} \mathrm{via}$ a step down service transformer - $12.47 / 2.3 \mathrm{kV}, 8$ MVA, leakage reactance: $5 \% \mathrm{pu}$, connection: $\mathrm{Yg}-\mathrm{Yg}$ ) and $1 \mathrm{MVA}$ passive load set (see Section IV-A) was modelled as a mixed load using DIgSILENT to validate the proposed VU emission separation methodology (see (20)).

The phasor diagram representation showing the individual emission contributions made by different unbalance sources is given in Fig. 4. These contributors and the corresponding emission vectors are:

- network (line), $V U F_{P O E, \text { line }}$

- passive load, $V U F_{P O E, P L}$

- source, $V U F_{\text {source }}$

- induction motor, $V U F_{P O E, I M}$

As in the cases of pure passive load and induction motor load, the resultant VU emission vectors at the POE established using the formulation and through simulation are in close agreement thus proving the validity of the formulation.

The general observation is that, although the unbalance emission at the POE is improved in the presence of the induction motor, the emission contribution that arise as a result of the passive load is relatively more significant and hence the resultant unbalance emission at the POE is greater than the pre-connection unbalance emission $\left(V U F_{\text {source }}\right)$ at the POE.

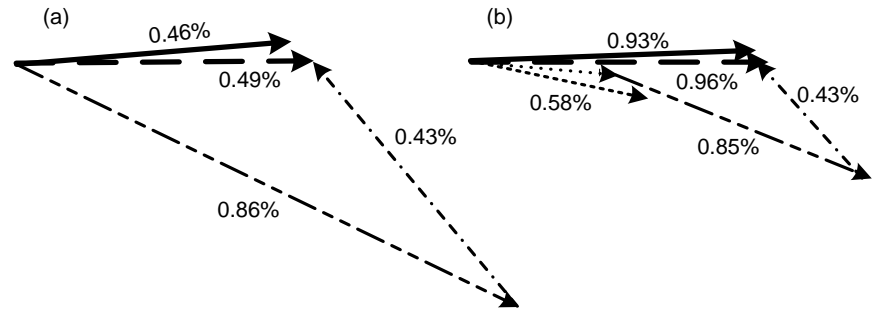

(c)

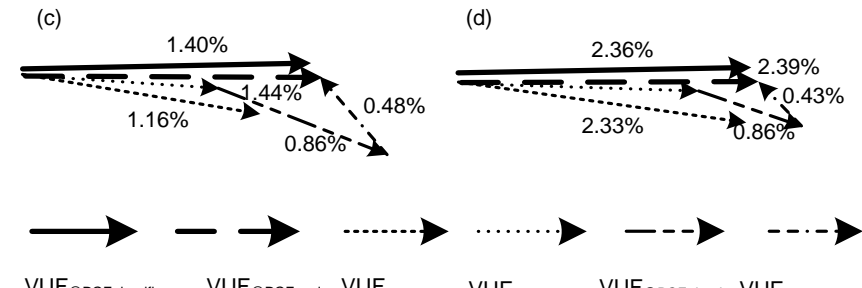

Fig. 4. Separation of VU emission at POE with different source unbalance levels: mixed load consiting a passive and an induction motor load, untransposed line. (a). $V U F_{\text {source }}=0 \%$ (b). $V U F_{\text {source }}=0.58 \%$ (c). $V U F_{\text {source }}$ $=1.16 \%$ (d). $V U F_{\text {source }}=2.33 \%$

\section{CONCLUSIONS}

This paper presented complex unbalance factor based formulations which can be used to evaluate the VU emission contributions made by different sources of unbalance at a POE utilising snap-shot measurements of the power system. Several major conclusions can be drawn from the work presented:

- The asymmetrical line contribution to the total VU emission at the POE has been evaluated as a decoupled quantity using the characteristic sequence impedance terms of the transmission line.

- A more generalised expression has been derived for the VU emission due to load (passive loads) asymmetry as given by the factor $\left(\left(V U F_{P O E}-C U F\right) \frac{V_{\text {reg-line }}}{1+V_{\text {reg-line }}}\right.$ which utilise only the pre-connection and post-connection voltage/current measurements at the POE.

- The ability of induction motors to attenuate the VU at the POE has been confirmed through this study quantifying the improvement.

- The effect of upstream source unbalance propagated to the POE has been separated in terms of $V U F_{\text {source. }}$

Based on the proposed approach, an advanced power quality instrument may be configured to monitor and record voltage/current measurements and switching status of loads/lines continuously which enable the assessment of VU as a continuous time domain function to accommodate dynamic behaviour of the power system. Such a set up may provide further investigation opportunities on the statistical approaches given in IEC documents on voltage unbalance management.

\section{APPENDIX A}

SEQUENCE CURRENTS IN THE RADIAL SYSTEM: PROOF OF (8) AND (9)

$U_{1 \text {,rec }}$ and $U_{2 \text {,rec }}$ at the POE can be expressed in terms of load current and load impedance $\left(Z_{L}=Z_{\text {rec }}\right)$ as shown in 
(A.1) and (A.2)

$$
\begin{aligned}
& U_{1, \text { rec }}=Z_{11, \text { rec }} I_{1}+Z_{12, \text { rec }} I_{2} \\
& U_{2, \text { rec }}=Z_{21, \text { rec }} I_{1}+Z_{22, \text { rec }} I_{2}
\end{aligned}
$$

$I_{1}$ can be derived approximating $U_{1 \text {,rec }}=Z_{11 \text {,rec }} I_{1}$, since the voltage drop of $Z_{12 \text {,rec }} I_{2}$ is negligible compared to the contribution caused by the voltage drop given by $Z_{11 \text {,rec }} I_{1}$ on $U_{1, \text { rec }}{ }^{4}$ Hence, the positive sequence current, $I_{1}$, can be established as;

$$
I_{1}=\frac{U_{1, \mathrm{rec}}}{Z_{11, \mathrm{rec}}}
$$

From (A.2), the negative sequence current, $I_{2}$, flowing through the system can be expressed as;

$$
I_{2}=\frac{U_{2, \mathrm{rec}}-Z_{21, \mathrm{rec}} I_{1}}{Z_{22, \mathrm{rec}}}
$$

Replacing the positive sequence current $I_{1}$ in (A.4) with (A.3), the expression for $I_{2}$ can be further rearranged as follows.

$$
I_{2}=-\frac{Z_{21, \text { rec }} U_{1, \text { rec }}}{Z_{11, \text { rec }} Z_{22, \text { rec }}}+\frac{U_{2, \text { rec }}}{Z_{22, \text { rec }}}
$$

\section{APPENDIX B}

VU EMISSION MADE BY LOAD ASYMMETRY: PROOF OF

The VU that arises as a result of load asymmetries $\left(V U F_{\text {load }}\right)$ as given in (14) is;

$$
V U F_{\text {load }}=\frac{Z_{21, \text { rec }}}{Z_{11, \text { rec }}} \frac{V_{\text {reg-line }}}{\left(1+V_{\text {reg-line }}\right)}
$$

Rewriting the revised receiving end (load end) sequence voltages as shown in (B.1) and (B.2), the ratio of $\frac{Z_{11, \text { rec }}}{Z_{21 \text {,rec }}}$ can be calculated as shown in (B.3).

$$
\begin{array}{r}
U_{1, \text { rec }}=Z_{11, \text { rec }} I_{1} \\
U_{2, \text { rec }}=Z_{21, \text { rec }} I_{1}+Z_{22, \text { rec }} I_{2}
\end{array}
$$

Then;

$$
\begin{gathered}
Z_{11, \text { rec }}=\frac{U_{1, \text { rec }}}{I_{1}} \\
Z_{21, \text { rec }}=\frac{U_{2, \text { rec }}-Z_{22, \text { rec }} I_{2}}{I_{1}} \\
\frac{Z_{21, \text { rec }}}{Z_{11, \text { rec }}}=\frac{U_{2, \text { rec }}-Z_{22, \text { rec }} I_{2}}{U_{1, \text { rec }}}
\end{gathered}
$$

Utilising the fact that the positive sequence impedance is equal to the negative sequence impedance for all passive loads, Eqn. (B.3) can be rearranged as:

$$
\frac{Z_{21, \mathrm{rec}}}{Z_{11, \mathrm{rec}}}=V U F_{P O E}-C U F
$$

where $V U F_{P O E}$ is the $\mathrm{VU}$ factor at the POE which is given by $\frac{U_{2, \mathrm{rec}}}{U_{1, \mathrm{rec}}}$ and $C U F$ is the current unbalance factor given by $\frac{I_{2}}{I_{1}}$.

${ }^{4}$ Sensitivity studies undertaken using unbalanced load flow studies indicate

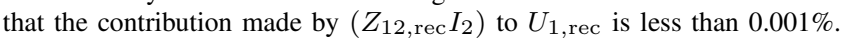

\section{APPENDIX C \\ Voltage UnBALANCE EMISSION DATA}

The data used to generate the phasor diagrams presented in Figs 2, 3 and 4 are presented in Tables I, II and III respectively.

Decoupled VU emission contributions ( $V U F_{\text {load }}, V U F_{\text {line }}$ and $\left.V U F_{P O E, I M}\right)$ derived only through the proposed formulation are shown in the tables for brevity. But, It has been validated that the same values can be obtained through simulations considering specific cases of the simulated power system. That is, making one component unbalanced at a time, while keeping the rest of the system balanced, the VU level at the POE gives the contribution made by that individual unbalanced component.

\section{REFERENCES}

[1] 'Electromagnetic compatibility (EMC) - limits - assessment of emission limits for the connection of unbalanced installations to $\mathrm{MV}, \mathrm{HV}$ and EHV power systems', Technical report IEC/TR 61000-3-13, Ed. 1 International Electrotechnical Commission, 2008

[2] 'Electromagnetic compatibility (EMC) - limits - assessment of emission limits for distorting loads in MV and HV power systems', Technical report IEC/TR 61000-3-6, Ed. 1, International Electrotechnical Commission, 1996.

[3] 'Electromagnetic compatibility (EMC) - limits - assessment of emission limits for fluctuating loads in MV and HV power systems, Technical report IEC/TR 61000-3-7', Ed.1,International Electrotechnical Commission, 1996.

[4] Von Jouanne A, Banerjee B "Assessment of voltage unbalance", Power Delivery, IEEE Transactions on, vol.16, no.4, pp.782-790, Oct 2001.

[5] Z Emin, D S Crisford "Negative phase-sequence voltages on E\&W transmission system", Power Delivery, IEEE Transactions on, vol.21, no.3, pp.1607-1612, July 2006

[6] Seiphetlho T E, Rens A P J "On the assessment of voltage unbalance", Harmonics and Quality of Power (ICHQP), 2010 14th International Conference on, pp.1-6, 26-29 Sept. 2010.

[7] Mayordomo J G, Beites L F, Gutierrez J L "Assessment of unbalance emission level produced by loads using the apparent power components", European Transactions on Electrical Power (1996), 6: 381386.

[8] Prabodha Paranavithana, 'Contributions Towards the Development of the Technical Report IEC/TR 61000-3-13 on Voltage Unbalance Emission Allocation', Ph.D. dissertation, School of Electrical, Computer and Telecommunications Engineering, University of Wollongong, Australia, March 2009.

[9] Prabodha Paranavithana and Sarath Perera "Location of Sources of Voltage Unbalance in an Interconnected Network", in Proc. IEEE Power Engineering Society General Meeting, Calgary, Alberta, Canada, July 2009.

[10] Prabodha Paranavithana, Sarath Perera, Danny Sutanto and Robert Koch, "A Systematic Approach Towards Evaluating Voltage Unbalance Problem in Interconnected Sub-transmission Networks: Separation of Contribution by Lines, Loads And Mitigation", Proc. 13th International Conference on Harmonics and Quality of Power, ICHQP 2008, Wollongong-Australia, Sept.-Oct. 2008.

[11] 'Review of disturbance emission assessment techniques', CIGRE/CIRED C4.109 WG Report 468, June 2011

[12] Renner H, "Voltage unbalance emission assessment", Electric Power Quality and Supply Reliability Conference (PQ), 2010, vol.16, no.18, pp.43-48, June 2010.

[13] Prabha Kundur, 'Power System Stability and Control', McGraw-Hill, Inc., pp. 271-274, 1993.

[14] Paul C. Krause, Oleg Wasynczuk, Scott D. Sudhoff, 'Analysis of Electric Machinery and Drive Systems'Second Ed., John Wiley and Sons Inc., pp165, 2002. 
TABLE I

VOLTAGE UNBALANCE EMISSION DATA USED TO GENERATE PHASOR DIAGRAMS FOR CONSTANT POWER LOAD

\begin{tabular}{|c|l|l|l|l|l|}
\hline$\#$ & Simulation results & \multicolumn{3}{l|}{ Proposed formulation results } \\
\hline & $\begin{array}{l}\text { Source unbalance } \\
\left(V U F_{\text {source }}\right) \%\end{array}$ & $\begin{array}{l}\text { VU at POE } \\
(\text { Loadflow) } \\
\left(V U F_{P O E}\right) \%\end{array}$ & $\begin{array}{l}\text { VU made by load } \\
\left(V U F_{P O E, \text { load }}\right) \\
\%\end{array}$ & $\begin{array}{l}\text { VU made by line } \\
\left(V U F_{P O E, \text { line }}\right) \\
\%\end{array}$ & $\begin{array}{l}\text { Calculated } \\
\text { VU } \\
\left(V U F_{P O E, \text { cal }}\right) \\
\%\end{array}$ \\
\hline $\mathrm{a}$ & $0.0 \angle 0.0$ & $0.72 \angle 69.5$ & $1.15 \angle 23.0$ & $0.78 \angle 167.9$ & $0.68 \angle 63.7$ \\
\hline $\mathrm{b}$ & $0.58 \angle 90.2$ & $1.29 \angle 78.2$ & $1.17 \angle 23.2$ & $0.78 \angle 167.8$ & $1.25 \angle 75.3$ \\
\hline $\mathrm{c}$ & $1.0 \angle 120.0$ & $1.72 \angle 103.9$ & $1.06 \angle 34.0$ & $0.76 \angle 167.7$ & $1.65 \angle 102.6$ \\
\hline $\mathrm{d}$ & $2.08 \angle 43.9$ & $3.00 \angle 49.2$ & $1.40 \angle 25.2$ & $0.77 \angle 167.8$ & $2.99 \angle 47.7$ \\
\hline
\end{tabular}

TABLE II

VOLTAGE UNBALANCE EMISSION DATA USED TO GENERATE PHASOR DIAGRAMS FOR AN INDUCTION MOTOR LOAD

\begin{tabular}{|c|c|c|c|c|c|}
\hline \multirow[t]{2}{*}{ \# } & \multicolumn{2}{|l|}{ Simulation results } & \multicolumn{3}{|c|}{ Proposed formulation Results } \\
\hline & $\begin{array}{l}\text { Source/ upstream } \\
\text { unbalance } \\
\left(V U F_{\text {source }}\right) \\
\%\end{array}$ & $\begin{array}{l}\text { VU at POE } \\
\left(V U F_{P O E}\right) \%\end{array}$ & $\begin{array}{l}\text { VU made by line } \\
\left(V U F_{P O E}, \text { line }\right) \%\end{array}$ & $\begin{array}{l}\text { Source } \\
\text { modified by } \mathrm{IM} \\
\left(V U F_{P O E, I M}\right) \\
\%\end{array}$ & $\begin{array}{l}\text { Calculated } \\
\text { VU at POE } \\
\left(V U F_{P O E, \text { cal }}\right) \\
\%\end{array}$ \\
\hline $\bar{a}$ & $0.0 \angle 0.0$ & $0.17 \angle-168$ & $0.16 \angle-168.7$ & $0 \angle 0$ & $0.16 \angle-168$ \\
\hline $\mathrm{b}$ & $0.58 \angle 29.8$ & $0.32 \angle 45.8$ & $0.16 \angle-168.7$ & $0.47 \angle 34.0$ & $0.32 \angle 45.3$ \\
\hline $\mathrm{c}$ & $1.16 \angle 29.6$ & $0.79 \angle 38.7$ & $0.16 \angle-168.7$ & $0.94 \angle 33.7$ & $0.79 \angle 38.3$ \\
\hline $\mathrm{d}$ & $2.33 \angle 29.3$ & $1.72 \angle 35.8$ & $0.16 \angle-168.7$ & $1.88 \angle 33.5$ & $1.73 \angle 35.5$ \\
\hline
\end{tabular}

TABLE III

VOLTAGE UNBALANCE EMISSION DATA USED TO GENERATE PHASOR DIAGRAMS FOR A MIXED LOAD

\begin{tabular}{|c|c|c|c|c|c|c|}
\hline \multirow[t]{2}{*}{$\#$} & \multicolumn{2}{|l|}{ Simulation results } & \multicolumn{4}{|c|}{ Proposed formulation results } \\
\hline & $\begin{array}{l}\text { Source/ upstream } \\
\text { unbalance } \\
\left(V U F_{\text {source }}\right) \\
\%\end{array}$ & $\begin{array}{l}\text { VU at POE } \\
\left(V U F_{P O E}\right) \%\end{array}$ & $\begin{array}{l}\text { VU made by } \\
\text { passive load } \\
\left(V U F_{P O E, P L}\right) \%\end{array}$ & $\begin{array}{l}\text { VU made by line } \\
\left(V U F_{P O E}, \text { line }\right) \%\end{array}$ & $\begin{array}{l}\text { Source } \\
\text { modified by } \mathrm{VU} \\
\left(V U F_{P O E, I M}\right) \\
\%\end{array}$ & $\begin{array}{l}\text { Calculated } \\
\text { VU at POE } \\
\left(V U F_{P O E, \mathrm{cal}}\right) \\
\%\end{array}$ \\
\hline $\mathrm{a}$ & $0.0 \angle 0$ & $0.46 \angle 44.12$ & $0.86 \angle 21.27$ & $0.43 \angle 178.42$ & $0 \angle 0$ & $0.49 \angle 41.06$ \\
\hline $\mathrm{b}$ & $0.58 \angle 29.8$ & $0.93 \angle 39.08$ & $0.85 \angle 21.17$ & $0.43 \angle 178.47$ & $0.48 \angle 34.24$ & $0.96 \angle 37.6$ \\
\hline $\mathrm{c}$ & $1.16 \angle 29.7$ & $1.40 \angle 37.24$ & $0.86 \angle 20.92$ & $0.48 \angle 178.46$ & $0.95 \angle 34.06$ & $1.44 \angle 36.22$ \\
\hline
\end{tabular}
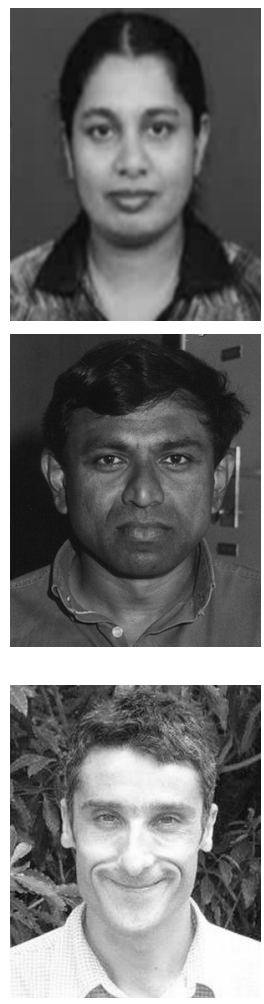
Machines, Power System Harmonics and Power System Reliability.

U. Jayatunga (S'2010) received the B.Sc.(Eng) degree in electrical power engineering and a M.Sc. degree in electrical engineering from the University of Moratuwa, Sri Lanka. Currently she is pursuing studies towards the Ph.D. degree at the University of Wollongong, Australia. Her research interests are in power quality and power system analysis.

S. Perera (M'1995) received the B.Sc.(Eng) degree in electrical power engineering from the University of Moratuwa, Sri Lanka, a M.Eng.Sc. degree from the University of New South Wales, Australia, and the Ph.D. degree from the University of Wollongong, Australia. He has been a lecturer at the University of Moratuwa, Sri Lanka. Currently he is an Associate Professor with the University of Wollongong. He is the Technical Director of the Endeavour Energy Power Quality and Reliability Centre at the University of Wollongong.

P. Ciufo (SM'2007) graduated from the University of Wollongong with a B.E. (Hons) in Electrical Engineering in 1990 whilst also completing an Industry Cadetship. He obtained an M.E. (Hons) in Electrical Engineering in 1993. He joined the academic staff of the University after completing his Ph.D. in 2002. Dr Ciufo has had various stints in industry as an electrical engineer and returned to academia in 2007. His research interests include Modelling and Analysis of Power Distribution Systems, Distribution Automation, Modelling and Analysis of AC 